Int. J. Electrochem. Sci., 14 (2019) 5777 - 5793

International Journal of

ELECTROCHEMICAL

SCIENCE

WWW.electrochemsci.org

\title{
Structural Origin of Corrosion Inhibition Effect over 2-(2- Hydroxyphenyl)benzothiazole on Steel in $\mathrm{HCl}$ Medium
}

\author{
Shenying Xu ${ }^{1,2}$, Wenpo Li ${ }^{1,{ }^{*}}$, Xiuli Zuo ${ }^{3}$, Dongdong Zheng ${ }^{1}$, Xingwen Zheng ${ }^{1,4}$, Shengtao Zhang ${ }^{1}$ \\ ${ }^{1}$ School of Chemistry and Chemical Engineering, Chongqing University, Chongqing 400044, PR \\ China \\ ${ }^{2}$ School of Chemistry and Chemical Engineering, Yibin University, Yinbin 644000, PR China \\ ${ }^{3}$ Department of Oil Application \& Management Engineering, Logistic Engineering University, \\ Chongqing 401331, PR China \\ ${ }^{4}$ School of Chemical and Pharmaceutical Engineering, Sichuan University of Science \& Engineering, \\ Zigong 643000, PR China \\ *E-mail: cqwpli@126.com
}

doi: $10.20964 / 2019.06 .20$

Received: 4 February 2019 / Accepted: 19 March 2019 / Published: 10 May 2019

The inhibition effect of 2-(2-Hydroxyphenyl)benzothiazole (HBT), a newly synthesized benzothiazole derivative, on mild steel in $1 \mathrm{M} \mathrm{HCl}$ medium has been investigated by utilizing weight loss measurements, electrochemical methods and morphology characterization. The results indicate that HBT exhibited a superior corrosion inhibition efficiency, which reached approximately $95 \%$ with the addition of $0.07 \mathrm{mM} \mathrm{HBT}$. Electrochemical tests illustrate that HBT is a mixed-type inhibitor. According to the Langmuir adsorption isotherm, the thermodynamic and kinetic parameters of the adsorption process complied with a physical-adsorption mechanism. Furthermore, computational calculations based on density functional theory reveal the relation between the electronic properties and the inhibition efficiency. In combination with the value of $p K_{a}$, the protonic form of HBT in corrosive medium was predicted.

Keywords: mild steel, benzothiazole derivative, electrochemical measurement, computational study, corrosion inhibition

\section{$\underline{\text { FULL TEXT }}$}

(C) 2019 The Authors. Published by ESG (www.electrochemsci.org). This article is an open access article distributed under the terms and conditions of the Creative Commons Attribution license (http://creativecommons.org/licenses/by/4.0/). 